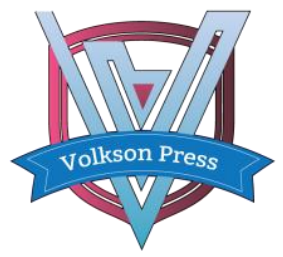

Economics, Finance and Statistics (EFS)

DOI : http://doi.org/10.26480/icefs.01.2018.69.75

\title{
SOCIAL MEDICAL INSURANCE AND ECONOMIC GROWTH
}

\author{
Zheng Lili \\ School of insurance, Central University of Finance and Economics, Beijing, China \\ *Corresponding Author Email: zhengll@cufe-ins.sinanet.com
}

This is an open access article distributed under the Creative Commons Attribution License, which permits unrestricted use, distribution, and reproduction in any medium, provided the original work is properly cited.

\section{ARTICLE DETAILS}

\section{Article History:}

Received 12 March 2018 Accepted 12 April 2018 Available online 15 May 2018

\section{ABSTRACT}

This paper analyzes the social medical insurance's impact on economic growth from the perspective of physical capital and human capital. Combined with unique account of the social medical insurance model, this paper established a representative individual model to discuss the relationship between social medical insurance relationship and economic growth. Our study found that the contribution rate of personal account will produce multiplier effect on economic growth, but the contribution rate of pooling account depends on parameters in the model. The results of numerical simulation show that the higher rate of economic growth is with the lower rate of pooling account payment and the higher rate of personal account payment. We also find that the proportion of employment payment transferring to personal account is relevant to economic growth. The empirical results also verify the positive impact of social medical insurance on economic growth. The results of theoretical model, numerical simulation and empirical analysis provide a theoretical basis for speeding up the reform of the basic medical insurance system in china.

\section{KEYWORDS}

Social Medical Insurance, Physical Capital, Human Capital, Economic Growth.

\section{INTRODUCTION}

China has undergone drastic reforms of public health insurance in just over ten years. The reform which covers medical insurance system urban group (that is publicly funded free medical care) and rural cooperative medical system gradually withdraw from history. In the city, the medical insurance provided by employee is gradually replaced by the social medical insurance, and the governments in rural areas are striving for the establishment of a new medical insurance system.

China's social medical insurance system has covered all of the groups now. The insured number is 1.336 billion and accounted for $97 \%$ in 2015.The insurance fund have total revenue of 1.603 trillion and paying of 1.354 trillion yuan. Among them, financial subsidies have played an important role in expanding coverage of medical insurance, because $80 \%$ of the total population groups needs government subsidies for medical insurance. The government subsidies accounted for $82.09 \%$ of social insurance fund income in 2011. Social medical insurance is an important part of the social security system as kind of means of social justice system and redistribution and has great significance to residents' medical needs and development of the healthy China. Our country is in the important stage of social medical insurance reform with the aging of the population, changes of disease spectrum, changes of the ecological environment, the way of life and a series of challenges to the health. The current social medical insurance of China is facing huge amount of the transformation cost such as integration, so social medical insurance as a social "stabilizer", still needs government investments. In the premise of government limited resources, research on the economic effect of social medical insurance for the reform of social security system is very important.

On the other hand, the development is still the top priority. China's economy has been shown signs of slowing down after years of rapid growth. China's economic growth rate in 2016 is $6.7 \%$, which is the lowest level since 1991, shows that China's economy faces very great pressure. Because medical insurance is closely related to social and economic development, and social medical insurance can protect people in the prevalence of medical and health services utilization of financial accessibility, by playing the role of economic compensation, to change family constraints and economic incentives facing, thus affecting consumption, savings and other micro economic decision factors [1-5]. Then these decision factors will influence the accumulation of physical capital and human capital formation and have effect on the overall economy. Therefore, it is very necessary to study how to realize the coordinated development and mutual promotion of social medical insurance and economy in china.

Social medical insurance is designed to maintain fairness and social welfare as a major public policy and have a wide and profound influence on all aspects of social life, it affects the personal savings, consumption and investment in microeconomic decisions by changing the insured's budget constraint the welfare and status, and it will affect the economic operation of the accumulation of physical capital and human capital formation, inevitably have an impact on economic growth. This paper attempts to answer the following questions: what is the relationship between social medical insurance and economic growth? Does social medical insurance promote economic growth or inhibit economic growth? How does the social medical insurance system affect the physical capital, human capital and economic growth in China? How can China's social medical insurance system reform promote economic growth? In this paper, we analysis economic growth of the social medical insurance based on China's current environmental parameters and investigate path and the effect of social medical insurance on economic growth, to describe deeply function of social medical insurance system on economic growth in China, find the impetus of economic growth from the perspective of social medical insurance, and provide a theoretical basis for speeding up the reform of social the medical insurance system in China, as well as provide empirical support for developing scientific and reasonable social medical insurance policy.

\section{REVIEWS OF RELATED LITERATURES}

The theory of economic growth theory affirmed the effect of the physical capital, human capital and other factors on the economic growth. Based on a study, because of the contribution of Douglas North, economists began 
to pay close attention to the role of system on economic growth $[6,7]$.

Study on the impact of social insurance on economic growth and mainly concentrates in two aspects: one is from perspective of social insurance, physical capital and economic growth. The new classical school analyzes the social insurance effect on economic growth by studying the impact of social insurance on the savings and the accumulation of physical capital. A researcher argues that the social insurance system can change consumer spending and saving behavior by changing the budget constraints faced by consumers [8]. The life cycle hypothesis of a researcher and the overlapping generation's model of another researcher study the effect of social security on the saving $[9,10]$. A researcher also suggested that the substitution effect of social insurance led to the decrease of total savings, which led to the slow economic growth in 1960s to 1970s in the United States [11]. Study showed while the decline of the savings rate in the United States after World War II, all kinds of insurance, the unemployment, pension, disability benefits and health insurance continue to increase, and make the conclusion that medical insurance payment instead of self-pay can reduce $12 \%$ of the savings [12]. According to a researcher the implementation of social medical insurance in Taiwan can reduce savings by an average of $8.6 \%$ to $13.7 \%$ through empirical data. A group of researchers found that the level of social insurance expenditure has a significant linear and nonlinear effect on urban residents' savings per capita level [13]. Some scholars have also compared the influence of different social insurance system on economic growth. Neo classical growth theory holds that the pay as you go system will have a "crowding out" effect on savings, but the fund system will increase the savings rate, thereby promoting economic growth.

Another is from perspective of social insurance, human capital and economic growth. After a group of researcher's classic research on the role of human capital on the economic growth, scholars began to explore the impact of social insurance on economic growth from the perspective of human capital accumulation $[14,15]$. The new growth theory implies that human capital accumulation is the only source of long-run economic growth. The new growth school takes human capital as social security variables influence the economic growth, the impact of human capital and social security from the perspective of the formation process to demonstrate the effects of social security on economic growth. A researcher explained the social security is conducive to economic growth from externalities of human capital [16]. Based on a study, the social insurance system will promote people to increase the investment of human capital, thereby promoting economic growth [17].

\section{SIMULATION ANALYSES}

Our simulations employ a multi-period overlapping generation's model developed by a group of researchers within a general equilibrium framework $[18,19]$. By explicitly taking into social medical insurance, the effect of the social medical insurance influence economic growth as well as savings, physical capital and human capital through changing the budget constraints facing individuals. The model consists of the individuals, the private firm, and the government.

Social medical insurance affects economic growth mainly through two ways: one is through budget constraints which influent the behavior of individual savings, thus affecting the formation of physical capital in the economy; two is the current and future welfare which change the individual medical expenditure and human capital, thus affect the economic impact of human capital accumulation.

\subsection{The Model}

\subsubsection{The Individual}

A theoretical model considering a representative individual model and the life cycle is divided into two phases: phase 0 (first period) and 1 (next period). In the first period they are healthy, and they work. In the second period they are retired, and they may become ill.

The individual is in health physical condition current and get income through labor and pay social medical insurance premiums according to the provisions of the social medical insurance; in the next period, the sick probability of representative individuals is $\mathrm{P}$, if the individual is sick, he need to pay medical expenses which is equivalent of $M$ and can reimbursement by some proportion of medical expenses ${ }^{1}$.

The utility function: because medical services affect the individual health status, it is assumed that the number of medical services is expressed by medical expenses, so medical expenditure is into utility function [20]. We assume that life cycle utility of individual depends on the utility $c_{t}$ of the first period and $c_{t+1}$ of the second period, as well as medical expenses $m_{t}$ in second period. Assuming there is no altruism bequest motivation, and Ricardo equivalence does not hold. Without loss of generality, the utility function of the individual is assumed to be:

$$
u\left(c_{t}, c_{t+1}, m_{t}\right)=\ln c_{t}+\rho \ln c_{t+1}+p \varphi \ln m_{t}
$$

Where $\rho$ and $\varphi$ denote time discount factor and the discount rate of utility of medical expense. The utility function is a strictly concave increasing function.

Health human capital function: health production function depends on the medical service and health production time investment and human capital stock according to a researcher [21]. Because personal health is affected by many factors, so inputs have rich connotation. In this paper, because the main concern is about medical insurance on economic growth, therefore we assume that the individual's health is mainly decided by the medical expenses and the stock of human capital. Therefore, the individual health human capital accumulation equation is given by:

$$
h_{t+1}=D m_{t}^{\theta} h_{t}^{1-\theta}
$$

Where D represents the production technology of human capital and is constant. $\theta$ reflects contribution rate of medical expenditure on human capital, and $h_{t}{ }^{2}$ denote the stock of human capital, and $1-\theta$ can be interpreted as transfer of the current stock of human capital to the next period.

Budget constraints: the individual budget constraints are that the entire life cycle of consumers spending is not greater than the income. $\left(1-\tau_{i}-\tau_{p}\right) w_{t}$ represents net income of a representative individual which is used for $c_{t}, s_{t}, c_{t+1}$, as well as $\sigma m_{t}$ which denote selfpaid medical expenses after illness. The budget constraints of the two phases are:

$$
\begin{gathered}
c_{t}=\left(1-\tau_{i}-\tau_{p}\right)\left(1-s_{t}\right) w_{t} \\
c_{t+1}=\left(1+r_{1+t}\right) s_{t}\left(1-\tau_{i}-\tau_{p}\right) w_{t}-m_{t}+p(1-\sigma) m_{t}+\left(\tau_{i}+\eta \tau_{p}\right) w_{t}
\end{gathered}
$$

(3) and (4) merge together into :

$$
\left[\left(1+r_{1+t}\right)\left(1-\tau_{i}-\tau_{p}\right)+\left(\tau_{i}+\eta \tau_{p}\right)\right] w_{t}-p \sigma m_{t}-c_{t+1}-\left(1+r_{1+t}\right) c_{t}=0
$$

\subsubsection{The Firm}

Suppose the economy is completely competitive, the economy has only one enterprise and one product, the output has constant returns to scale, and production function includes human capital, and output is determined by physical capital and human capital. Based on a research, the existing literature has proposed many ways of human capital on effective labor input and output levels [22-23]. Such as the healthier individuals may be more energetic, and the probability of illness will be smaller, and thus can bear more effective and intensity of work. On the other hand, the improvement of the health level can also improve the individual's cognitive efforts, which can improve the individual's learning ability and the return of education. Therefore, it can be assumed that individuals with higher health human capital will have a higher production capacity or have more effective labor in the unit time.

The firm is assumed to maximize its profits, taking the wage rate and the interest rate as given. The wage rate and the interest rate are determined in perfectly competitive factor markets in equilibrium. The aggregate private production function is assumed to be Cobb- Douglas such that

$$
Y_{t}=A K_{t}^{\alpha} L_{t}^{1-\alpha}=A K_{t}^{\alpha}\left(h_{t} N_{t}\right)^{1-\alpha}
$$


Where $A$ denotes technology of production of the private sector. $Y_{t}$ represents aggregate output at time t, $K_{t}$ the aggregate private capital stock, $L_{t}$ aggregate labor supply measured in the effective labor unit. Effective labor depends on the number of workers and healthy human capital. And $A>0, \quad 0<\alpha<1$. Maximum firm's profit $\pi_{t}=A K_{t}^{\alpha}\left(h_{t} N_{t}\right)^{1-\alpha}-\delta K_{t}-w_{t} L_{t}$, where $\delta$ representing the depreciation rate, and $w_{t}$ on behalf of labor price per unit, which is the wage rate; $1+r_{t}$ on behalf of capital price per unit, which is the interest rate. Assuming that each factor market is perfectly competitive with the above aggregate production function, output is fully distributed to labor and capital. The first order necessary conditions of the firm yield

$$
w_{t}=A(1-\alpha) k_{t}^{\alpha} h_{t}^{1-\alpha}, 1+r_{t}=\alpha A(k / h)^{\alpha-1}
$$

\subsubsection{The Government Sector}

According to the design of social medical insurance system in China, the social medical insurance account consists of a pooling account and a personal account. A personal account is mainly used to pay for outpatient medical expenses and can be carried forward. The pooling account is used to pay for the medical expenses of hospitalization. Social medical insurance is divided into two parts, one part is the pooling part, and another is personal account. Personal payment accounted for $\tau_{i}$ proportion of wages, Employer payment accounted for $\tau_{p}{ }^{3}$ proportion of wages $\tau_{p} \cdot \eta$ is employer payment transfer to individual account, then $1-\eta$ is employer payment transfer to pooling account. Assume that individual wage is $w_{t}$, and medical expenses are $m_{t}$ after sick. $\sigma$ denotes self-pay of medical expenses. The reimbursement from the pooling account is $B_{t}$, and the total cumulative amount of personal accounts is $A_{t}$. The income of social medical insurance fund is given by:

$$
B_{t}+A_{t}=(1-\eta) \tau_{p} w_{t}+\left(\tau_{i}+\eta \tau_{p}\right) w_{t}
$$

The expenditure of the social medical insurance fund depends on the medical expenditure of the sick individual and the expenditure of the pooling account:

$$
B_{t}+A_{t}=m_{t} p(1-\sigma)+\left(\tau_{i}+\eta \tau_{p}\right) w_{t}
$$

Since the implementation of the social medical insurance is to decide expenditure by revenue and the balance of payments, in order to maintain the balance of the fund balance, need to meet the condition:

$$
(1-\eta) \tau_{p} w_{t}=m_{t} p(1-\sigma) 。
$$

\subsection{The Model}

Given human capital, wages, interest rates, medical insurance premiums copayment of the representative of individual, medical insurance payment rate, the individual maximize the utility of whole life through the choice of consumption and medical expenses in the budget constraint. Therefore, the utility maximization problem can be stated as:

$$
\max _{c_{t}, c_{t+1}, m_{t}} u\left(c_{t}, c_{t+1}, m_{t}\right)
$$

s.t. $\left[\left(1+r_{1+t}\right)\left(1-\tau_{i}-\tau_{p}\right)+\left(\tau_{i}+\eta \tau_{p}\right)\right] w_{t}-p \sigma m_{t}-c_{t+1}-\left(1+r_{1+t}\right) c_{t}=0$

We constructed Lagrange function:
$L=\ln c_{t}+\rho \ln c_{t+1}+p \varphi \ln m_{t}+\lambda\left\{\left[\left(1+r_{1+t}\right)\left(1-\tau_{i}-\tau_{p}\right)+\left(\tau_{i}+\eta \tau_{p}\right)\right] w_{t}-p \sigma m_{t}-c_{t+1}-\left(1+r_{1+t}\right) c_{t}\right\}$

\subsubsection{Social medical insurance, savings and physical capital}

Solve the problem of representative individual maximization, then we can get the optimal consumption and optimal medical expenditure in different periods:

$$
\begin{gathered}
m_{t}=\left(1+r_{1+t}\right) \varphi c_{t} / \sigma \quad(14) \\
\lambda=\frac{(1+\rho)(1-\sigma)}{\left[(1-\sigma)\left(1+r_{1+t}\right)\left(1-\tau_{i}-\tau_{p}\right)+(1-\sigma)\left(\tau_{i}+\eta \tau_{p}\right)-\sigma(1-\eta) \tau_{p}\right] w_{t}} \\
c_{t}=\frac{(1-\sigma)\left(1+r_{1+t}\right)\left(1-\tau_{i}-\tau_{p}\right)+(1-\sigma)\left(\tau_{i}+\eta \tau_{p}\right)-\sigma(1-\eta) \tau_{p}}{(1+\rho)\left(1+r_{1+t}\right)(1-\sigma)} w_{t} \\
c_{t+1}=\frac{\left[(1-\sigma)\left(1+r_{1+t}\right)\left(1-\tau_{i}-\tau_{p}\right)+(1-\sigma)\left(\tau_{i}+\eta \tau_{p}\right)-\sigma(1-\eta) \tau_{p}\right] \rho}{(1+\rho)(1-\sigma)} w_{t}
\end{gathered}
$$

The optimal savings rate is:

$$
s_{t}=1-\frac{1}{1+\rho}-\frac{(1-\sigma) \tau_{i}+(\eta-\sigma) \tau_{p}}{(1+\rho)(1-\sigma)\left(1+r_{1+t}\right)\left(1-\tau_{i}-\tau_{p}\right)}
$$

The total saving rate is the individual optimal savings rate and the accumulation of individual accounts:

$$
S_{t}=1-\frac{1}{1+\rho}-\frac{(1-\sigma) \tau_{i}+(\eta-\sigma) \tau_{p}}{(1+\rho)(1-\sigma)\left(1+r_{1+t}\right)\left(1-\tau_{i}-\tau_{p}\right)}+\left(\tau_{i}+\eta \tau_{p}\right)
$$

Proposition 1: Since $0<1-\sigma<1$, as a result, the higher the contribution rate of individual accounts to social medical insurance, the lower of the personal savings rate. The contribution rate of pooling account payment rate is fuzzy and depending on the symbol of $\eta-\sigma$. If the high proportion of $\eta$, the low proportion of self-pay of $\sigma$, and the value of $\eta-\sigma$ is positive and greater, as a result the pooling account rate $\tau_{p}$ is high, the personal savings rate is low.

The contribution of personal account to individual savings rate is reflected in: there is an optimal savings rate, when the contribution of personal account does not exceed the level of voluntary savings rate, and tax of personal account equal to the rate of return of individual voluntary savings rate, the individual will reduce savings to maintain the original optimal, and if this effect is one to one, when personal account payment rate increases by $1 \%$, the saving rate will reduce by $1 \%$. The main reason for this is that the representative individual predicts that the money in this account will be returned when he is ill, so that it can reduce the private voluntary savings, and will not change its consumption plan. From the perspective of the whole society, the total savings rate does not change, and then there is the equivalent effect of voluntary savings and involuntary savings, so the impact of individual accounts on the total savings rate is neutral.

The contribution rate of the social pooling account is the transferring proportion of the healthy population to the sick people. On the one hand, the higher the transfer rate, the less saving resources for the healthy population, thereby reducing the optimal voluntary savings rate; on the other hand, the higher the transfer rate, the more personal compensation after the illness, so if personal can expected this situation, he will reduce precautionary savings. But the conclusion of the model also shows that the proportion of transferring to the individual account and copayment will affect the results, as the higher the social pooling account transferring to the individual account, and the lower copayment, the savings rate is less, which also compared with the economic intuition, consistent with the conclusions of classic literature. 
The total wealth of the economy is equal to the voluntary private savings of all individuals and the individual account fund of medical insurance. If there is no intergenerational loss, the capital is fully depreciated in each period, the total wealth of society is $W_{t}=N_{t}\left[s_{t} w_{t}+\left(\tau_{i}+\eta \tau_{p}\right) w_{t}\right]$.
If the economy is closed, the equilibrium conditions of the capital market is $K_{t+1}=W_{t}=N_{t}\left[s_{t} w_{t}+\left(\tau_{i}+\eta \tau_{p}\right) w_{t}\right]$, The capital accumulation equation is $K_{t+1} / N_{t}=k_{t+1}=\left(s_{t}+\tau_{i}+\eta \tau_{p}\right) w_{t}$, then

$$
\begin{array}{r}
k_{t+1}=\left[\frac{\rho}{1+\rho}-\frac{(1-\sigma) \tau_{i}+(\eta-\sigma) \tau_{p}}{(1+\rho)(1-\sigma)\left(1+r_{1+t}\right)\left(1-\tau_{i}-\tau_{p}\right)}+\tau_{i}+\eta \tau_{p}\right] w_{t} \\
\text { Because } w_{t}=A(1-\alpha) k_{t}^{\alpha} h_{t}^{1-\alpha}, \text { the capital accumulation equation is } \\
k_{t+1}=A(1-\alpha)\left[\frac{\rho}{1+\rho}-\frac{(1-\sigma) \tau_{i}+(\eta-\sigma) \tau_{p}}{(1+\rho)(1-\sigma)\left(1+r_{1+t}\right)\left(1-\tau_{i}-\tau_{p}\right)}+\tau_{i}+\eta \tau_{p}\right] k_{t}^{\alpha} h_{t}^{1-\alpha} \\
\frac{k_{t+1}=A(1-\alpha)\left[\frac{\rho}{1+\rho}-\frac{(1-\sigma) \tau_{i}+(\eta-\sigma) \tau_{p}}{(1+\rho)(1-\sigma)\left(1+r_{1+t}\right)\left(1-\tau_{i}-\tau_{p}\right)}+\tau_{i}+\eta \tau_{p}\right] k_{t}^{\alpha-1} h_{t}^{1-\alpha}}{k_{t}}\left[\begin{array}{l}
(1+2)
\end{array}\right.
\end{array}
$$

Proposition 2: the contribution rate of personal account and pooling account of social medical insurance to the accumulation of physical capital is fuzzy. One the one hand, the pooling account of social medical insurance will reduce the personal savings rate, one the other hand, the consumption fund can change to accumulation fund from the whole society, thereby increasing capital accumulation, so the overall effect is fuzzy.

\subsubsection{Social medical insurance and medical expenditure}

Solving the optimization equation to obtain the representative individual medical expenditure:

$$
m_{t}=\frac{\varphi(1-\sigma)\left(1+r_{1+t}\right)\left(1-\tau_{i}-\tau_{p}\right)+(1-\sigma)\left(\tau_{i}+\eta \tau_{p}\right)-\sigma(1-\eta) \tau_{p}}{(1+\rho)(1-\sigma) \sigma} w_{t}
$$

The proportion of medical expenditure to wages is

$$
\frac{m_{t}}{w_{t}}=\frac{\varphi(1-\sigma)\left(1+r_{1+t}\right)+(1-\sigma)\left[1-\left(1+r_{1+t}\right) \varphi\right] \tau_{i}+\left[\eta-\varphi(1-\sigma)\left(1+r_{1+t}\right)\right] \tau_{p}}{(1+\rho)(1-\sigma) \sigma}
$$

Proposition 3: the contribution rate of personal account of social medical insurance to medical expenditure depends on $1-\left(1+r_{1+t}\right) \varphi$, if $\varphi<1 /\left(1+r_{1+t}\right)$ With the rise of personal account payment rate, the proportion of medical expenditure to wages will rise, this is because the individual account can deduct medical expenses, so the rise of payment rate means an increase in personal account funds, so the medical expenditure will increase.

The overall account payment rate $\tau_{p}$ on medical expenditure depends on $\eta-\varphi(1-\sigma)\left(1+r_{1+t}\right)$. So the pooling account payment rate impact

$$
\frac{h_{t+1}}{h_{t}}=D m_{t}^{\theta} h_{t}^{1-\theta}=D\left\{A(1-\alpha) \frac{\varphi(1-\sigma)\left(1+r_{1+t}\right)\left(1-\tau_{i}-\tau_{p}\right)+(1-\sigma)\left(\tau_{i}+\eta \tau_{p}\right)-\sigma(1-\eta) \tau_{p}}{(1+\rho)(1-\sigma) \sigma} k_{t}^{\alpha} h_{t}^{1-\alpha}\right\}^{\theta} h_{t}^{-\theta}
$$

Proposition 4: the contribution rate of personal account and pooling account on the health human capital is fuzzy. The influence of individual account payment rate $\tau_{i}$ on health human capital depends on $1-\left(1+r_{1+t}\right) \varphi$, if $\varphi<1 /\left(1+r_{1+t}\right)$, the healthy human capital will medical expenditure in two aspects: on the one hand, the establishment of pooling account, and the proportion of payment $\eta$, makes the diseased individuals receive medical security, so individuals tend to increase medical costs; on the other hand is $\varphi(1-\sigma)\left(1+r_{1+t}\right)$, which means healthy individuals transferring to the illness individuals, the higher the transfer rate, the less the healthy individual resources. Therefore, the net effect of the pooling account payment rate on the proportion of medical expenditure is fuzzy, depending on the parameters of the model.

\subsubsection{Social medical insurance and health human capital}

$$
\begin{aligned}
& \stackrel{*}{k}=A^{-\frac{\theta}{\alpha}}(1-\alpha)^{-\frac{1+\theta}{\alpha}}\left[\frac{\rho}{1+\rho}-\frac{(1-\sigma) \tau_{i}+(\eta-\sigma) \tau_{p}}{(1+\rho)(1-\sigma)\left(1+r_{1+t}\right)\left(1-\tau_{i}-\tau_{p}\right)}+\tau_{i}+\eta \tau_{p}\right]^{\frac{1-\theta}{1+\theta \alpha-\alpha}} \\
& \left\{\frac{\varphi(1-\sigma)\left(1+r_{1+t}\right)\left(1-\tau_{i}-\tau_{p}\right)+(1-\sigma)\left(\tau_{i}+\eta \tau_{p}\right)-\sigma(1-\eta) \tau_{p}}{(1+\rho)(1-\sigma) \sigma}\right\}^{\frac{\theta}{\alpha^{2}-\alpha-\theta \alpha^{2}}}
\end{aligned}
$$

Similarly, in steady state $h_{t+1}=h_{t}=h^{*}$, then we get 


$$
\begin{aligned}
& h=A^{\frac{\alpha \theta-\alpha \theta^{2}-1-\theta}{\alpha-\alpha^{2}+\theta \alpha^{2}}} D^{\frac{1}{1-\alpha+\theta \alpha}}(1-\alpha)^{-\frac{2}{1-\alpha+\theta \alpha}}\left[\frac{\rho}{1+\rho}-\frac{(1-\sigma) \tau_{i}+(\eta-\sigma) \tau_{p}}{(1+\rho)(1-\sigma)\left(1+r_{1+t}\right)\left(1-\tau_{i}-\tau_{p}\right)}+\tau_{i}+\eta \tau_{p}\right]^{\frac{-\theta}{1+\theta \alpha-\alpha}} \\
& \left\{\frac{\varphi(1-\sigma)\left(1+r_{1+t}\right)\left(1-\tau_{i}-\tau_{p}\right)+(1-\sigma)\left(\tau_{i}+\eta \tau_{p}\right)-\sigma(1-\eta) \tau_{p}}{(1+\rho)(1-\sigma) \sigma}\right\}^{\frac{\theta-\alpha \theta}{\alpha^{2}-\alpha-\theta \alpha^{2}}}
\end{aligned}
$$

According to the theory of economic growth, when the economy is in the path of balanced growth, per capita output, per capita physical capital and human capital per capita will increase at the same rate, so $\frac{y_{t+1}}{y_{t}}=\frac{k_{t+1}}{k_{t}}=\frac{h_{t+1}}{h_{t}}=1+g_{t}=1+g_{k, t}=1+g_{h, t}$, so that the growth path of

$$
\begin{aligned}
& 1+g=A^{\frac{\theta}{1-\alpha(1-\theta)}} D^{\frac{1-\alpha}{1-\alpha(1-\theta)}}(1-\alpha)^{\frac{2 \alpha \theta-\alpha-\theta+1}{1-\alpha(1-\theta)}} \sigma^{\frac{\theta(\alpha-1)}{1-\alpha(1-\theta)}}\left[\left(1+r_{1+t}\right)\left(1-\tau_{i}-\tau_{p}\right)\right]^{\frac{1+\theta-\alpha}{1-\alpha(1-\theta)}}[(1-\rho)(1-\sigma)]^{\frac{-\theta}{1-\alpha(1-\theta)}} \\
& \frac{\left\{(1-\sigma)\left(1+r_{1+t}\right)\left(1-\tau_{i}-\tau_{p}\right)\left[\rho+(1+\rho)\left(\tau_{i}+\eta \tau_{p}\right)\right]-(1-\sigma) \tau_{i}-(\eta-\sigma) \tau_{p}\right\}^{\frac{\alpha-1}{1-\alpha(1-\theta)}}}{\left[\varphi(1-\sigma)\left(1+r_{1+t}\right)\left(1-\tau_{i}-\tau_{p}\right)+(1-\sigma)\left(\tau_{i}+\eta \tau_{p}\right)-\sigma(1-\eta) \tau_{p}\right]^{\frac{\theta(\alpha-1)}{1-\alpha(1-\theta)}}}
\end{aligned}
$$

The proposition 5 can be obtained by (28): the contribution rate of individual account and the pooling account on economic growth are fuzzy. The contribution rate of personal account on economic growth is reflected in: in the presence of insufficient effective demand, the contribution rate of personal account can replace the precautionary savings, which also has a multiplier effect, according to Keynes's theory, increasing of the personal account payment means that it creates the same demand, so demand will promote the production and output, in turn the increasing output will increase government financial income and employment. Then the contribution of each monetary unit will eventually lead to more than one monetary unit of total output growth, which is multiplier effect of the personal account payment rate on economic growth.

The impact of pooling account payment on economic growth mainly through the following two aspects: first, the impact of the accumulation of physical capital. According to proposition 1 , the pooling account affect the savings rate in two aspects and the net effect is negative, so too high pooling payment rate will reduce the accumulation of physical capital, so as to reduce the rate of economic growth; two is the social pooling account will affect the rate of medical expenditure, net effect of social pooling account rate is fuzzy according to propositions 2 , so there is the uncertain impact on economic growth. In a word, the net effect of pooling account balanced growth rate is $1+\mathrm{g}$ 。

The steady-state growth rate is obtained by simultaneous equations: contribution rate on economic growth depends on the parameters of the model.

\section{SIMULATION}

Through the analysis of the theoretical model, we can see that the individual account and the pooling account of social medical insurance have an impact on the individual savings rate, the accumulation of physical capital, human capital and economic growth. In order to explain and predict the influence of social medical on economic growth insurance in China, we calibrate the relevant parameters and analyze the results of numerical simulation. The following assumptions are made in order to get a realistic benchmark model. In this paper, we determined the parameters of the model according to the research results of the existing literature, which can avoid the arbitrariness of parameter settings and make the value of the parameters close to reality.

Follow research of previous, we get the reference values of the parameters of the following table, the basic parameters of decision model for the benchmark model, because of the economic mechanism of social medical insurance growth depends on the parameters, we will do the sensitivity analysis.

Table 3: The Values of Parameters

\begin{tabular}{|c|c|c|}
\hline parameter & meaning & 0.646 \\
\hline$\theta$ & the output elasticity of human capital production function & 0.4 \\
\hline$\alpha$ & The output elasticity of physical capital in production function & 0.78 \\
\hline$\rho$ & time preference factor & 0.3 \\
\hline$p$ & Probability of illness & 0.015 \\
\hline$r$ & Discount rate of medical expenditure & 0.02 \\
\hline$\tau_{i}$ & Social medical insurance premium by individual & 0.07 \\
\hline$\tau_{p}$ & Social medical insurance premium by employer & 0.01 \\
\hline$\eta$ & The proportion of employer contribution to individual account & 0.286 \\
\hline$\sigma$ & & \\
\hline$D$ & Technical parameters of health human capital & 2.13 \\
\hline$A$ & Technical parameters of production & 2.13 \\
\hline
\end{tabular}

\subsection{Benchmark Simulation}

Table 3 shows, numerical simulations of pooling account rates and savings rate and economic growth rate of on the assumption that the parameters show that: the pooling payment rate is higher, individual savings rate is lower and the social optimal savings rate is lower, therefore the lower the rate of economic growth. The overall increase of pooling rate of $15 \%$ will reduce the economic growth rate of about $0.796 \%$. This indicates that the government improve medical security level by improving the pooling account payment will reduce household savings rate, thereby reducing the accumulation of physical capital, although increasing of the pooling account rate has the incentive effect of human capital investment, but the effect on physical capital has played a leading role, so the net effect on economic growth is negative. This is consistent with the theoretical expectations and the previous simulation results.

Table 4: Pooling account rate, the Savings Rate and Economic Growth Rate

\begin{tabular}{|c|c|c|c|}
\hline $\begin{array}{c}\text { Pooling account } \\
\text { rate (\%) }\end{array}$ & $\begin{array}{c}\text { Individual } \\
\text { optimal savings } \\
\text { rate (\%) }\end{array}$ & $\begin{array}{c}\text { Social optimal } \\
\text { savings rate (\%) }\end{array}$ & $\begin{array}{c}\text { Economic growth } \\
\text { rate (\%) }\end{array}$ \\
\hline 0 & 0.46 & 0.49 & 10.958 \\
\hline 2 & 0.45 & 0.47 & 10.850 \\
\hline 4 & 0.44 & 0.46 & 10.643 \\
\hline 6 & 0.44 & 0.46 & 10.541 \\
\hline 8 & 0.44 & 0.45 & 10.344 \\
\hline 10 & 0.43 & 0.45 & 10.251 \\
\hline 15 & 0.42 & 0.45 & 10.162 \\
\hline
\end{tabular}


Table 4 shows that the simulation of individual account payment, savings rate and economic growth under the assumption of the current parameters: the higher the individual payment rate, the lower the savings rate, and the higher the economic growth rate. Individual account rates increased by $15 \%$ per year, then the economic growth rate will increase by about $1.23 \%$. This is due to the increase in the rate of personal account contribution, which help to increase the physical capital and reduce the individual's preventive savings for the disease, and healthy human capital will rise, thereby promoting economic growth.

Table 5: Personal account rate, savings rate and economic growth rate

\begin{tabular}{|c|c|c|c|}
\hline $\begin{array}{c}\text { Personal } \\
\text { account rate (\%) }\end{array}$ & $\begin{array}{c}\text { Individual } \\
\text { optimal savings } \\
\text { rate (\%) }\end{array}$ & $\begin{array}{c}\text { Social optimal } \\
\text { savings rate (\%) }\end{array}$ & $\begin{array}{c}\text { Economic growth } \\
\text { rate (\%) }\end{array}$ \\
\hline 0 & 0.427 & 0.427 & 8.199 \\
\hline 2 & 0.426 & 0.447 & 8.277 \\
\hline 4 & 0.426 & 0.467 & 8.885 \\
\hline 6 & 0.426 & 0.487 & 8.929 \\
\hline 8 & 0.426 & 0.506 & 9.214 \\
\hline 10 & 0.425 & 0.526 & 9.346 \\
\hline 15 & 0.424 & 0.575 & 9.429 \\
\hline
\end{tabular}

\subsection{Reform Simulations}

Next is the policy parameters test. According to the foregoing analysis, we can see that the proportion of employer payment transferring to individual account will affect economic growth, so we change the value of $\eta$ to see how to impact on economic growth.

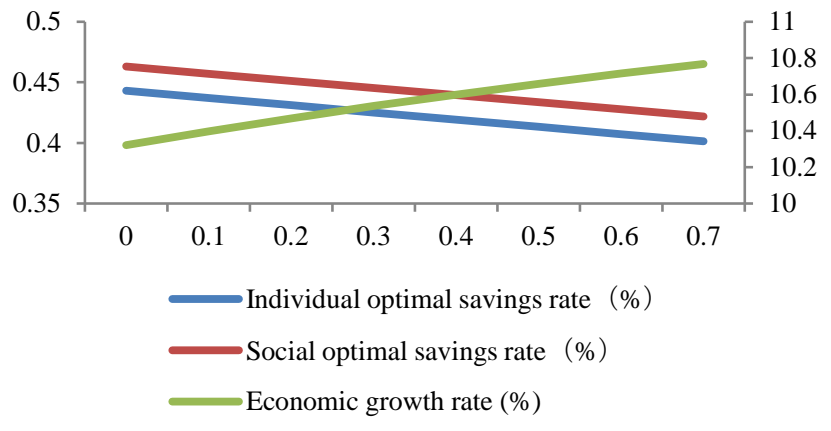

Figure 5: The proportion of employer account allocated to individual accounts and economic growth

We found that proportion of employer payment transferring to individual account can promote economic growth, which verifies the multiplier effect of the individual contribution rate to the economic growth.

\section{CONCLUSIONS AND POLICY RECOMMENDATIONS}

\subsection{Conclusions}

We analyze the social medical insurance's impact on economic growth from the perspective of human capital and physical capital. VAR model results show that medical insurance has an exogenous effect on human capital and economic growth and there is an obvious relationship. As long as the social medical insurance can promote the physical capital and human capital accumulation, and the individual can get protection and incentive combination from social medical insurance, there will be a virtuous cycle between social medical insurance and economic growth.

The dilemma of reform of social medical insurance is how to balance between fairness and efficiency and find the balance point, as long as the social medical insurance can continuously improve the physical capital and human capital and promote economic growth; we can solve the existing problems in the reform of medical insurance system.

Our study shows the following problems: one is the reform of the medical insurance system on improving the health status of residents; two is the social medical insurance is factors of promoting economic growth, so the financial investment in social medical insurance is not only the pure consumption and consumer spending, which is a kind of investment with future earnings three; lastly, relevant policies on social medical insurance should consider the relationship between social medical insurance, physical capital, human capital and economic growth, and the establishment of an incentive mechanism of the social medical insurance system to promote economic growth.

\subsection{Recommendations}

This paper argues that the following three policy priorities can be considered: First, China should let more people enjoy the protection of medical insurance. Although China's current medical insurance continues to spread, but in some remote areas, medical insurance and other social insurance coverage is not covered and did not achieve a comprehensive medical insurance. We should speed up the reform of the medical insurance system as soon as possible, which has a positive effect on China's economic development.

Second, the scientific development of medical insurance system can determine the appropriate level of economic and social development. Medical insurance is essential, but too high level of medical insurance is not conducive to economic development, which will take up much of the physical capital and cannot significantly improve human capital. Taking into account the fairness and efficiency of health insurance reform, in order to achieve long-term economic and social development.

Third, achieve national health insurance to balance regional development. we can see the difference of initial economic and development situation, the level of medical insurance and fund spending imbalance between provinces will eventually lead to the differences in economic strength. National co-ordination can adjust regional imbalances and achieve economic coordination and sustainable development.

\section{REFERENCES}

[1] Agenor, P.R., Meanides, K. 2006. The allocation of public Expenditure and Economic Growth, Political Economy, 115 (6), 925-985.

[2] Agenor, P.R. 2008. Health and infrastructure in a model of endogenous growth, Macroeconomics, 30, 1407-1422.

[3] Barro, R.J. 1996. Health and Economic Growth, paper presented at the Senior Policy Seminar on Health, human Capital and Economic Growth: Theory, Evidence and Policies, Pan American Health Organization and Inter-American Development Bank, Washington, DC.

[4] Bloom, D.E., Canning, D., Malaney, P.N. 2000. Demographic Change and Economic Growth in Asia, Population and Development Review, 26, 257290.

[5] Bloom, D.E., Canning, D. 2005. Health and Economic Growth : Reconciling the Micro and Macro Evidence, CDDRL Working Papers, Stanford Institute of International Studies, Stanford University.

[6] Carmichcel, B., Dissou, Y. 2000. Health insurance, liquidity and growth. The Scandinavian Journal of Economics, 102, 269-284.

[7] Fogel, Robert, W. 2002. Nutrition, Physiological Capital and Economic Growth, paper presented at the Senior Policy Seminar on Health, human Capital and Economic Growth: Theory, Evidence and Policies, Pan American Health Organization and Inter-American Development Bank, Washington, DC.

[8] Grossman, M. 1972. The Demand for Health: A Theoretical and Empirical Investigation, Columbia University Press.

[9] Hosoya, K., 2002. Health, Longevity, and the Productivity Slow down, Project on Intergenerational Equity, Institute of Economic Research, Hitotsubashi University, Discussion Paper Series, (25).

[10] Hoyt Bleakley, H. 2010. Health, Human Capital and Development. Annual Review of Economics, (2).

[11] Hosoya, K. 2003. Tax Financed Government Health Expenditure and Growth with Capital Deepening Externality, Economics Bulletin, (14), 110.

[12] Peter L., McMillan, J., Wacziarg, R. 2005. Death and Development, NBER Working Papers 11620, National Bureau of Economic Research. 
[13] Martin Fe Lucas, R. E. 1988. On the Mechanics of Economic Development, Journal of Monetary Economics, 22, 3-42.

[14] Mushkin, S.J. 1962. Health as an Investment, Political Economy, 70 (5), $129-157$

[15] Haiss, P., KjellSümegi. 2008. The Relationship of Insurance and Economic Growth A Theoretical and Empirical Analysis.

[16] Savedoff, W.D., Schultz, T.P. 2000. Earnings and the Elusive Dividends of Health, Wealth from Health, Washington, D.C., The InterAmerican Development Bank, 1-34.

[17] Solow, R.M.A. 1956. Contribution to the Theory of Economic Growth, Quarterly. Journal of Economics, (70), 165-194.

[18] Van Zon, A.H., Muysken, J. 2001. Health and Endogenous Growth, Journal of Health Economics, 20, 169-185.
[19] Webb, I.P., Grace, M.F., Skipper, H.D. 2002. The Effect of Banking and Insurance on the Growth of Capital And output, Center for Risk Management and Insurance Working Paper, 2-1.

[20] Van Zon, A.H., Muysken, J. 2001. Health and Endogenous Growth. Journal of Health Economics, 20, 169-185 .

[21] van Zon, A.H., Muysken, J. 2003. Health as a Principal Determinant of Economic Growth, Working paper, MERIT Infonomics Research Memorandum .

[22] Weil, D.N., 2007. Accounting for the Effect of Health on Economic Growth. Quarterly Journal of Economics, 122, 1265-1306.

[23] Giorgio, B., Carlotta, B. 2000. Social Security Expenditure and Economic Growth: an Empirical Assessment Research in Economics, Working Paper, 54, 249- 275. 